\title{
US-guided percutaneous core liver biopsy: analysis of 171 cases from a single oncology service
}

\author{
Francisco Victor Costa PARENTE ${ }^{1}$, Eder Alencar MOURA ${ }^{1,2}$, José Alexandre de Macêdo dos SANTOS ${ }^{1}$ and \\ Marcos Venício Alves LIMA²,3
}

Received 23/12/2017

Accepted 21/5/2018

\begin{abstract}
Background - Though strongly suggestive of metastasis, focal lesions on liver scans of oncological patients require histological confirmation for the prescription of adequate treatment. Objective - To evaluate the safety and efficacy of US-guided percutaneous core liver biopsy. Methods Descriptive, cross-sectional study based on secondary data from 171 patients submitted to US-guided percutaneous core liver biopsy at the diagnostic radiology service of the Ceará Cancer Institute (ICC, Brazil) between February 2010 and March 2015. Quantitative data were expressed in absolute numbers or percentages, with emphasis on the rate of complications observed within six hours after the procedure. Results - The overall accuracy was $96.4 \%$. The overall rate of complications was $2.3 \%$, three quarters of which was due to hemorrhage. Age over 50 years was positively associated with accuracy. No deaths occurred within the period of observation. Conclusion - Our findings support the claim that the use of thick biopsy needles improves diagnostic accuracy. The few complications observed were non-lethal and predominantly hemorrhagic.
\end{abstract}

HEADINGS - Neoplasm metastasis. Liver. Image-guided biopsy, adverse effects. Ultrasonography, methods.

\section{INTRODUCTION}

In oncology, biopsies are often used to confirm suspicion of malignancy. Despite the existence of a known primary tumor, the concurrent emergence of focal lesions on liver scans does not necessarily imply metastasis, but requires diagnostic confirmation by biopsy for the prescription of adequate treatment.

US-guided percutaneous core biopsies are currently considered an effective means of diagnosing lesions found almost anywhere in the body. In fact, in many scenarios it is the primary diagnostic method. Acceptance of this method is evidenced by its rapid dissemination over the past years, in step with the progressive drop in the use of diagnostic laparotomy ${ }^{(1)}$.

The liver may be biopsied with several techniques and approaches, including percutaneous blind biopsy, US-guided biopsy, CT-guided biopsy, transjugular biopsy and laparoscopic biopsy. In this study, only US-guided percutaneous core biopsy was used due to the possibility of real-time monitoring, which offers improved safety and accuracy, especially when biopsying abdominal and pelvic structures. Despite being operator-dependent, US has a range of advantages, including low cost and absence of ionizing radiation $^{(2,3)}$

There are, however, also contraindications for percutaneous core biopsy. According to some authors ${ }^{(4,5)}$, these include: A) Coagulation disturbance (confirmed by the presence of one or more of the following: prothrombin time $<60 \%$ of control, partial thromboplastin time $5 \mathrm{sec}$ longer than control, and platelet count $<60,000 / \mathrm{mm}^{3}$ ); B) Massive ascites (increased abdominal wall ten- sion, with echograhy-confirmed ascites refractory to treatment with diuretics); C) Accentuated chronic anemia associated with chronic kidney failure, hematocrit count $\leq 29 \%$, and use of anticoagulants (heparin); D) Morbid obesity (20\% above the ideal body weight).

Many types of biopsy needles are available on the market, with varying gauges, shapes and sample extraction mechanisms. In general, needles may be classified as thin (gauges 20-23) or thick (gauges 16-19). Thin needles are appropriate for collecting samples for cytological and, in some cases, histological studies. They can transgress the bowels at minimal risk and are associated with low rates of hemorrhage when used to sample vascularized lesions. Five or more fragments can be aspired with this type of needle ${ }^{(3)}$.

Thick needles provide more satisfactory samples for both cytological and histological studies (only 2-3 fragments are necessary). Moreover, certain types of benign and malignant lesions require larger samples for diagnosis. Though still considered low, the risk of hemorrhage is significantly greater for thick needles than for thin needles. It should therefore be verified on contrast CT or US Doppler before the procedure whether the lesion is highly vascularized or not ${ }^{(1,6)}$.

Liver biopsies are relatively safe, with an overall complication rate of $1 \%$ and a mortality rate of $0.1 \%$ or less when performed percutaneously. Most complications (60\%) occur within the first two hours, and $80 \%$ (with hemorrhage as the most common) occur within ten hours of the procedure. Hemorrhagic complications are more frequent in patients with malignancy and/or acute liver failure, chronic active hepatitis and cirrhosis ${ }^{(7)}$. At our service, patients are therefore observed for 24 hours after biopsies.

Declared conflict of interest of all authors: none

Disclosure of funding: no funding received

${ }^{1}$ Instituto do Câncer do Ceará (ICC), Diagnóstico por Imagem e Radiologia, Fortaleza, CE, Brasil. ${ }^{2}$ Universidade Estadual do Ceará (UECE), Faculdade de Medicina, Fortaleza, CE, Brasil. 3 Instituto do Câncer do Ceará (ICC), Cirurgia Oncológica, Fortaleza, CE, Brasil.

Corresponding author: Marcos Venício Alves Lima. Orcid: 0000-0002-4944-5022. E-mail: drmarcosvenicio@gmail.com 
The primary objective of this study was to evaluate the diagnostic accuracy and safety of US-guided percutaneous core liver biopsy in patients attending a diagnostic imaging and radiology service in Northeastern Brazil. The secondary objectives were:

- Describe the US-guided percutaneous core biopsy technique adopted at our service, including post-biopsy care and management of complications.

- Identify the main causes of inconclusive results.

\section{METHODS}

In this descriptive, cross-sectional study, we analyzed secondary data from an intentional sample of 171 patients submitted to USguided percutaneous core liver biopsy at the diagnostic imaging and radiology service of Haroldo Juaçaba Hospital (Ceará Cancer Institute / ICC), covering the period February 2010 to March 2015. The patients were identified by a search in the digital histopathology archives of the ICC pathology service (Patho Control 8), using the descriptors "hepatic" and "liver".

Thus, the sample consisted of patients with hepatic lesions detected by imaging, with or without a known primary tumor, referred to our service by their physicians (most often oncologists) for the determination of etiology.

Demographic, laboratory and clinical data were retrieved from the patients' records, including platelet and hematocrit count, prothrombin and thromboplastin time, histopathological and immunohistochemical findings, and information on postoperative complications.

The results were expressed as absolute (n) and relative frequency $(\%)$, mean, median, maximum and minimum values and standard deviation. All analyses were performed with IBM SPSS Statistics, v. 21.0. The study protocol was approved by the ICC research ethics committee and filed under entry \#44484915.0.0000.5528.

The standard procedure for US-guided percutaneous core liver biopsy used at our service is based on Khatie and coworkers ${ }^{(2)}$.

1. Review clinical indications for the procedure. Analyze previous imaging test results if available to make sure the use of US guidance is safe for the patient.

2. Check whether the patient's coagulation status allows to carry on the biopsy with safety. If not, ask the patient's physician (or a hematologist) to prescribe treatment to restore normal values.

3. Obtain the patient's informed written consent.

4. Perform biopsy under local anesthesia with $2 \%$ lidocaine.

5. Provide postoperative care.

6. Check the quality control of the pathological report to determine the percentage and causes of unsuccessful biopsies.

In the absence of contraindications (steps 1 and 2), written consent was requested. Before signing the form, patients were given relevant information about the procedure, including the reason for the biopsy and the possible occurrence of complications (e.g., bleeding and infection) and postoperative pain (the latter is rarely important and easily controlled with proper analgesics). Likewise, patients were informed about the need to remain in postoperative observation to monitor for and manage complications, if any.

Prior to the biopsy, 12 hours of fasting was required. Following the recommendations of Shankar and coworkers ${ }^{(1)}$, the vast majority of the biopsies were performed with the patient in a comfortable supine position, although in some cases other positions (e.g., oblique, and lateral or ventral decubitus) were preferred in order to reduce the distance to the target, favoring diagnostic accuracy. Only local anesthesia was used. Sedative or analgesic medication was not administered routinely. A peripheral venous access was provided for hydration.

The patients in this study were biopsied with thick needles (18 gauge) in order to collect at least two fragments of each lesion. Stored in labelled vials with formaldehyde, the samples were sent to the laboratory for pathological evaluation.

After the procedure, common dressing was applied to the wound. The patients were then placed in lateral decubitus on top of the biopsy site for a 2-hour rest with monitoring of vital signs (pulse and arterial pressure) and possible complaints at 30-min intervals. This was followed by a 4-hour rest in dorsal decubitus (totaling 6 hours of observation at our service). Then the patients were submitted to abdominal echography for the detection of liquid in the abdominal cavity (an indirect sign of hemorrhagic complications). If negative, the patients were allowed to eat and transferred to a ward for observation until completing 24 hours.

\section{RESULTS}

In our sample of 171 patients, the male sex was slightly predominant (89 vs 82) (TABLE 1). At the time of biopsy, the average age was 61.5 years (range: 26-89; median 63; mode 72).

As shown in TABLE 1, most procedures were performed in patients over 50 years of age, regardless of sex, due to the indicating a positive association between cancer and age related to cellular aging and progressive loss of cell recovery capabilities.

TABLE 1. Demographic and diagnostic data of 171 patients submitted to US-guided percutaneous core liver biopsy at the Ceará Cancer Institute, Brazil. February 2010 to March 2015.

\begin{tabular}{lll}
\hline \multicolumn{1}{l}{$\mathrm{n}$} & $\%$ \\
\hline Sex & & \\
$\quad$ Female & 82 & 48.0 \\
$\quad$ Male & 89 & 52.0 \\
Age & & \\
$\quad \leq 50$ & 31 & 18.6 \\
$>50$ & 136 & 81.4 \\
Number of fragments & & \\
$\quad 1$ & 52 & 30.6 \\
$>1$ & 118 & 69.4 \\
Size of fragment & & \\
$\quad \leq 1.2 \mathrm{~cm}$ & 90 & 52.9 \\
$>1.2 \mathrm{~cm}$ & 80 & 47.1 \\
Overall accuracy & 165 & 96.4 \\
\hline
\end{tabular}

All patients had preoperative laboratory findings in the safe range for the procedure, except one case of coagulation disturbance promptly treated and corrected by the patient's physician. The lowest platelet count observed was $80,000 / \mathrm{mm}^{3}$.

Most patients (69.4\%) had more than one fragment extracted. Nearly half the fragments $(47.1 \%)$ were larger than $1.2 \mathrm{~cm}$. Results were satisfactory for 165 patients, corresponding to an overall accuracy of $96.4 \%$. The remainder $(n=6 ; 3.6 \%)$ were inconclusive. 
In the present study, age over 50 years was the only factor influencing overal accuracy $(P=0.044)$ (TABLE 2).

TABLE 2. Influence of demographic and diagnostic factors on the accuracy of US-guided percutaneous core liver biopsy in a sample of 171 patients biopsiedat theCearáCancer Institute, Brazil.February 2010 to March 2015.

\begin{tabular}{llc}
\hline & Accuracy & $P$-value \\
\hline Sex & & \\
Female & $97.6 \%(80 / 82)$ & 0.466 \\
Male & $94.3 \%(84 / 89)$ & \\
Age & & \\
$\leq 50$ & $90.3 \%(28 / 31)$ & 0.044 \\
$>50$ & $97.8 \%(133 / 136)$ & \\
Number of fragments & & \\
$\quad 1$ & $94.2 \%(49 / 52)$ & 0.293 \\
$>1$ & $97.5 \%(115 / 118)$ & \\
Size of fragment & & \\
$\leq 1.2 \mathrm{~cm}$ & $95.6 \%(86 / 90)$ & 0.493 \\
$>1.2 \mathrm{~cm}$ & $97.5 \%(78 / 80)$ & \\
& &
\end{tabular}

In the group of inconclusive results, the average number of extracted fragments was 1.5, and the average fragment size was 1.2 $\mathrm{cm}$. Only two patients with inconclusive results had repeat biopsies. One of these had three fragments extracted, the largest of which measuring $1.4 \mathrm{~cm}$, but once more the presence of extensive fibrosis/ necrosis prevented reaching a conclusion. The other had two fragments extracted, the largest of which measuring $1.7 \mathrm{~cm}$, yielding a satisfactory result, despite the presence of fibrosis/necrosis.

The histopathological and immunohistochemical analyses identified primary liver tumors in 15 patients, secondary tumors in 117, indifferentiated neoplasia in 19, and non-neoplastic lesions in 3. In 11 patients, no lesion was found.

In the group of 117 secondary tumors, the most frequent type was biliodigestive, followed by neuroendocrine, coloretal, squamous cell and breast (FIGURE 1).

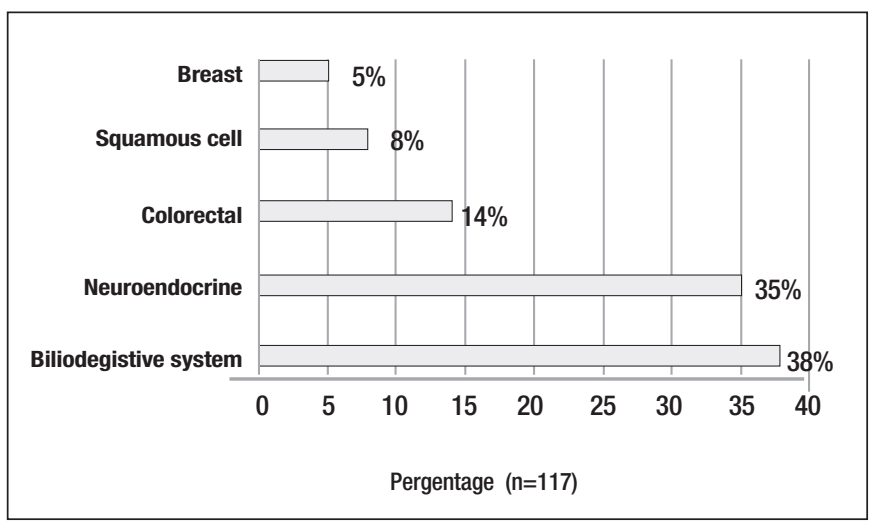

FIGURE 1. Distribution of relative frequency of secondary liver tumors in 117 out of a sample of patients submitted to US-guided percutaneous core liver biopsy at the Ceará Cancer Institute, Brazil. February 2010 to March 2015.
The four complications observed in the sample of 171 patients were predominantly hemorrhagic and correspond to an overall rate of $\sim 2.3 \%$. Half were early occurrences ( $<6$ hours) and half were late occurrences (6-24 hours) (TABLE 3). No deaths were observed during the 24-hour observation period adopted at our institution.

TABLE 3. Complications of US-guided percutaneous core liver biopsy according to type and time of occurrence in a sample of 171 patients biopsied at the Ceará Cancer Institute, Brazil. February 2010 to March 2015.

\begin{tabular}{lccc}
\hline Complications & $\begin{array}{c}\text { Early } \\
(<6 \mathrm{~h})\end{array}$ & $\begin{array}{c}\text { Late } \\
(6-24 \mathrm{~h})\end{array}$ & Total \\
\hline Transient hypotension (vasovagal reaction) & - & 1 & 1 \\
Intraperitoneal hemorrhage & 2 & - & 2 \\
Intrahepatic or subcapsular hematoma & - & 1 & 1 \\
\hline
\end{tabular}

\section{DISCUSSION}

Although it is a common situation in oncology, synchronic or metachronous liver lesions, even using US, CT-scan and MRI, may still raise doubts as to its neoplastic nature, as well as whether it is a new primary or metastatic lesion. Under these circumstances the US-guided needle biopsy appears as a low-cost, safe and accurate option $^{(8,9)}$.

At our service, thick needles (18 gauge) are preferred as they provide samples more easily interpreted by pathologists, minimizing the need for repeat biopsies due to inconclusive results. On the other hand, hemorrhagic complications are more frequent with thick needles than with thin needles ${ }^{(6)}$. According to Shankar and colleagues, ${ }^{1}$ the thicker the needle, the more accurate the diagnosis and the higher the rate of complications. This may be true in some settings, but in this study the rate of complications was low, no urgency surgical intervention was necessary, and the few complications observed were non-lethal. While core biopsy with thin needles is associated with high diagnostic accuracy and a low rate of complications, it requires the availability of an experienced cytopathologist. Core biopsy with thick needles ( $<19$ gauge) does not ${ }^{(3)}$.

The observed complications were predominantly $(75 \%)$ hemorrhagic (intraperitoneal hemorrhage and intrahepatic or subcapsular hematoma). Hemorrhage is a common complication and the main cause of mortality in the follow-up of biopsy patients. It usually results from the inadvertent perforation of a dilated portal vein or aberrant arteries and may cease spontaneously or, if severe, require blood transfusion and surgical intervention ${ }^{(10)}$.

Other much less common complications have been described in the literature, including peritonitis, septicemia, pneumothorax and hemothorax. One of our patients presented transient vasovagal hypotension, a minor complication easily corrected with hydration. Pain was not classified as a complication in this study since it is inherent to invasive procedures, short-lived, easily managed and non-life-threatening.

In one study, overall positivity was found to be independent of needle gauge, but 21 gauges was associated with the greatest levels of safety ${ }^{(6)}$. In our sample, conclusive and inconclusive results did not differ significantly with regard to fragment size and number. However, most inconclusive results were associated with extensive fibrosis/necrosis. In other words, conclusiveness was not dependent on fragment size and number, but poor fragment quality (i.e., extensive fibrosis/necrosis) compromised diagnostic accuracy and was the main reason for repeat biopsies. 


\section{CONCLUSION}

The preference for thick needles in US-guided percutaneous core liver biopsies is justified by the high accuracy achieved and the small percentage of inconclusive results. In this study, age over 50 years had a significant impact on accuracy, reflecting the well-documented association between cancer and old age. Few complications were observed, most of which were hemorrhagic, but none resulted in death. The presence of extensive fibrosis/necrosis in the samples compromised diagnostic accuracy and was the main reason for repeat biopsies.

\section{Authors' contribution}

Parente FVC: made substantial contributions to conception and design, acquisition of data; and in drafting the article. Moura EA: made contributions to acquisition of data; and analysis of data. Santos JAM: participated in doing the biopsies, drafting the article and revising it critically. Lima MVA: made substantial contributions to conception and design, wrote part of the article, gave final approval of the version to be submitted and revised version.

Parente FVC, Moura EA, Santos JAM, Lima MVA. Biópsia percutâneas de lesões hepática guiada por ultrassonografia: análise de 171 casos de um único centro oncológico. Arq Gastroenterol. 2018,55(3):208-11.

RESUMO - Contexto - Lesões focais nos exames de imagem do fígado em pacientes oncológicos, embora sejam achados fortemente sugestivos de envolvimento metastático, permanece a necessidade de confirmação histológica, a fim de que se institua uma terapia apropriada. Objetivo - Verificar a segurança e a eficácia do procedimento de biópsia hepática percutânea guiada por ultrassom, realizado pelo serviço de Radiologia e Diagnóstico por Imagem do Instituto do Câncer do Ceará (ICC). Métodos - Estudo transversal, descritivo, baseado em dados secundários de 171 pacientes, submetidos a biópsias hepáticas percutâneas, guiadas por ultrassonografia, realizadas no ICC, de fevereiro de 2010 a março de 2015. Os dados quantitativos obtidos foram apresentados em forma de números absolutos ou percentuais, com ênfase nas taxas de complicações, ocorridas nas primeiras seis horas de observação hospitalar. Resultados - A acurácia geral foi de 96,4\%. Encontramos uma taxa global de complicações de 2,3\%, sendo que 75\% delas foram de natureza hemorrágica. Não verificamos a ocorrência de óbitos dentro do período de observação pós-biópsia. Conclusão - A utilização de agulhas calibrosas, parece, de fato, estar relacionada à melhoria na acurácia diagnóstica, com baixas taxas de complicações, sobretudo as hemorrágicas, contudo não letais. No presente trabalho, a idade mostrou-se um fator modificador da acurácia.

DESCRITORES - Metástase neoplásica. Fígado. Biópsia guiada por imagem, efeitos adversos. Ultrassonografia, métodos.

\section{REFERENCES}

1. Shankar S, Sonnenberg E van, Silverman SG, Tuncali K. Interventional radiology procedures in the liver. Clin Liver Dis. 2002;6:91-118.

2. Khati NJ, Gorodenker J, Hill MC. Ultrasound-guided biopsies of the abdomen. Ultrasound Q. 2011;27:255-68.

3. Kim W, Shin SS. Ultrasound-guided percutaneous core needle biopsy of abdominal viscera: tips to ensure safe and effective biopsy. Korean J Radiol. 2017; 18:309-22.

4. Maciel AC, Barros SGS, Tarasconi DP, Severo Júnior LCV, Cerski CTS, Ilha DO, Experiência em pacientes com suspeita de hepatopatia crônica e contra-indicação para biópsia hepática percutânea utilizando a agulha de Ross modificada. Rev. Assoc. Med. Bras. 2000;46:134-42.

5. Lipnik AJ, Brown DB. Image-guided percutaneous abdominal mass biopsy: technical and clinical considerations. Radiol Clin North Am. 2015;53:1049-59.
6. Li GP, Gong GQ, Wang XL, Chen Y, Cheng JM, Li CY. Fine needle aspirating and cutting is superior to Tru-cut core needle in liver biopsy. Hepatobiliary Pancreat Dis Int. 2013;12:508-11.

7. Rumack CM, Wilson SR, Charboneau JW. Tratado de ultrassonografia diagnóstica. 4 ed. São Paulo: Guanabara Koogan; 2012.

8. Appelbaum L Kane RA, Kruskal JB, Romero J, Sosna J. Radiology. Focal hepatic lesions: US-guided biopsy--lessons from review of cytologic and pathologic examination results 2009;250:453-8.

9. Tzortzis D, Revenas K, Deladetsima I, Antoniou E, Tzortzis G Percutaneous US-guided liver biopsy in focal lesions using a semiautomatic device allowing to perform multiple biopsies in a single-pass. Minerva Gastroenterol Dietol. 2012;58:1-8.

10. Chuah SY. Review Article: Liver biopsy - past, present and future. Singapore Med J. 1996;37:86-90. 